\title{
Adding cows to the reference population makes a small dairy population competitive
}

\author{
J. R. Thomasen, ${ }^{*}{ }^{1}$ A. C. Sørensen, $\dagger$ M. S. Lund, $\dagger$ and B. Guldbrandtsen $\dagger$ \\ *VikingGenetics, DK 8860, Assentoft, Denmark \\ †Center for Quantitative Genetics and Genomics, Department of Molecular Biology and Genetics, Faculty of Science and Technology, \\ Aarhus University, DK-8830, Tjele, Denmark
}

\section{ABSTRACT}

Small dairy breeds are challenged by low reliabilities of genomic prediction. Therefore, we evaluated the effect of including cows in the reference population for small dairy cattle populations with a limited number of sires in the reference population. Using detailed simulations, 2 types of scenarios for maintaining and updating the reference population over a period of $15 \mathrm{yr}$ were investigated: a turbo scheme exclusively using genotyped young bulls and a hybrid scheme with mixed use of genotyped young bulls and progeny-tested bulls. Two types of modifications were investigated: (1) number of progeny-tested bulls per year was tested at 6 levels: 15 , $40,60,100,250$, and 500; and (2) each year, 2,000 firstlactation cows were randomly selected from the cow population for genotyping or, alternatively, an additional 2,000 first-lactation cows were randomly selected and typed in the first $2 \mathrm{yr}$. The effects were evaluated in the 2 main breeding schemes. The breeding schemes were chosen to mimic options for the Danish Jersey cattle population. Evaluation criteria were annual monetary genetic gain, rate of inbreeding, reliability of genomic predictions, and variance of response. Inclusion of cows in the reference population increased monetary genetic gain and decreased the rate of inbreeding. The increase in genetic gain was larger for the turbo schemes with shorter generation intervals. The variance of response was generally higher in turbo schemes than in schemes using progeny-tested bulls. However, the risk was reduced by adding cows to the reference population. The annual genetic gain and the reliability of genomic predictions were slightly higher with more cows in the reference population. Inclusion of cows in the reference population is a rapid way to increase reliabilities of genomic predictions and hence increase genetic gain in a small population. An economic evaluation shows that genotyping of cows is a profitable investment.

Received January 6, 2014.

Accepted May 23, 2014.

${ }^{1}$ Corresponding author: jotho@vikinggenetics.com
Key words: genotyped cow, genomic selection, genomic breeding plan

\section{INTRODUCTION}

In genomic selection (GS), the effects of dense sets of genetic markers are estimated in a reference population of genotyped and phenotyped individuals (Meuwissen et al., 2001). The estimated effects of the markers are then used to predict genomically enhanced breeding values (GEBV) for selection candidates. In dairy cattle, until now, reference populations mostly consisted of progeny-tested sires with reliably predicted EBV. These EBV include information from hundreds or thousands of daughters. Expanding the reference population has been shown to be an efficient way to increase reliabilities of GEBV (Lund et al., 2011; Wiggans et al., 2011).

Small dairy cattle populations are often restricted by small reference populations of progeny-tested bulls. These populations, therefore, have low reliabilities of GEBV (Thomasen et al., 2012). This poses a challenge for their future genetic gain. Thomasen et al. (2014) showed that low reliability of genomic prediction is the most important factor limiting genetic gain in smaller populations with more intensive use of young bulls without a progeny test. Therefore, an important objective for smaller dairy cattle breeds is to increase reliabilities of GEBV. Increasing the amount of information within a breed can be achieved either by increasing the number of progeny-tested bulls included in the reference population or by including genotyped females with their own records directly in the reference population.

Genotyping cows have become more relevant with decreasing costs of genotyping in general. In the Nordic cow population, a very high proportion of the cows have phenotypic recordings for all the traits in the breeding goal (Lauritsen, 2012). This makes genotyping of cows an option for increasing reliabilities of genomic predictions. Buch et al. (2012a) showed that a reference population consisting of all cows with a specific phenotype resulted in higher reliability compared with a reference population only including the proofs of the 
sires of these cows in the reference population. Similarly, to maximize the accuracy of GEBV, Van Grevenhof et al. (2012) found that the same individuals should be genotyped and phenotyped instead of genotyping parents and phenotyping their progeny.

Therefore, higher genetic gain and less inbreeding (Daetwyler et al., 2007) due to higher reliabilities of genomic predictions are to be expected in a small dairy cattle population where (1) genotyped females with their own phenotypic records are added to the existing sire reference population, or (2) the annual number of progeny-tested bulls included in the reference population is increased.

These effects were evaluated in 2 main breeding schemes. The turbo scheme exclusively used genotyped young bulls and the hybrid scheme used a mix of genotyped young bulls and progeny-tested bulls. The turbo scheme was expected to result in lower reliabilities because sires of the young breeding candidates are not in the reference population (Thomasen et al., 2012). Thus, genotyping of cows will contribute relatively more information to the turbo scheme. Therefore, we hypothesized that genotyped females would contribute relatively more to a higher genetic gain in the turbo scheme compared with the hybrid scheme, because the genomic information is used more intensively in the turbo scheme.

In the present study, we tested these hypotheses by evaluating the merit of adding genotypes of bulls and cows to the reference population in terms of monetary genetic gain, inbreeding, reliability of GEBV, and variability of the genetic gain in 2 different breeding schemes. Finally, an economic evaluation of genotyping cows for the reference population was performed.

\section{MATERIALS AND METHODS}

\section{Strategies for Maintaining Future Reference Population}

To test the hypotheses, 2 overall strategies for maintaining and updating the reference population were investigated for both the hybrid and turbo breeding schemes: (1) the number of progeny-tested bulls (PB) was varied between 15 and 500 at 6 different levels (B15, B40, B60, B100, B250, B500). Because a fixed progeny test capacity of 6,000 daughters of test bulls per year was assumed, the daughter group size was varied from 400 (B15) to 12 (B500) daughters per bull. In all turbo scenarios, the number of young bulls (YB) used as bull sires was 15. (2) Each year, 2,000 firstlactation cows were randomly genotyped (COW2000) adding up to 30,000 cows for the period of the $15 \mathrm{yr}$, or alternatively an additional 4,000 first-lactation cows were randomly genotyped the first 2 yr (COW4000) and, in the remaining $13 \mathrm{yr}, 2,000$ cows were randomly selected and genotyped, for a total of 34,000 genotyped cows over the whole period. The COW4000 scenario was designed to evaluate the effect of increasing the reliabilities of the genomic predictions more intensively compared with COW2000. The scenarios COW2000 and COW4000 were only simulated in the hybrid and turbo reference schemes with 60 bulls progeny-tested annually.

\section{Breeding Schemes}

The hybrid scheme $(\mathbf{H})$ reflected the current genomic breeding scheme in the Danish Jersey breed. The 15 YB (1 to 4 yr old) with the highest GEBV were selected and mated to $25 \%$ of the cow population. Additionally, 4 PB (5 to 6 yr old) were selected for $75 \%$ of the inseminations in the cow population. These PB were available since semen had been stored or the bulls were alive when their daughter proofs became available. The turbo scheme ( $\mathbf{T})$ used only YB; therefore, the generation interval was reduced.

In both schemes, the simulated population consisted of 20,000 cows with records from 100 herds, which reflect the part of the cow population where the bull calves are recruited. The majority of cows that produce cows were not simulated. The 1,500 cows with the highest EBV for the breeding goal across all herds were chosen as bull dam candidates. It is generally thought that 1,500 screened bull dams inseminated with relevant bull sires are required to obtain 500 bull calves that fulfill the criteria for genotyping (P. G. Larson, VikingGenetics, Randers, Denmark, personal communication). These cows produced 500 genotyped bull calves, where $60 \mathrm{YB}$ were selected annually for progeny testing according to their GEBV. The YB obtained 100 daughter records for the production trait (PT) and 92 daughter records for the functional trait (FT).

The breeding schemes were chosen to mimic practically feasible options for the Danish Jersey cattle population as an example of a small dairy cattle population. A more detailed description of the breeding scheme parameters can be found in Thomasen et al. (2014).

\section{Experimental Design}

A stochastic finite locus model was used to simulate the different breeding strategies. The populations were simulated in 3 steps: (1) 500 generations of a historic population for build-up of linkage disequilibrium (LD) and a pool of segregating QTL; this step was computationally intensive and was shared between all scenarios and all replicates; (2) $20 \mathrm{yr}$ of a conventional progeny- 


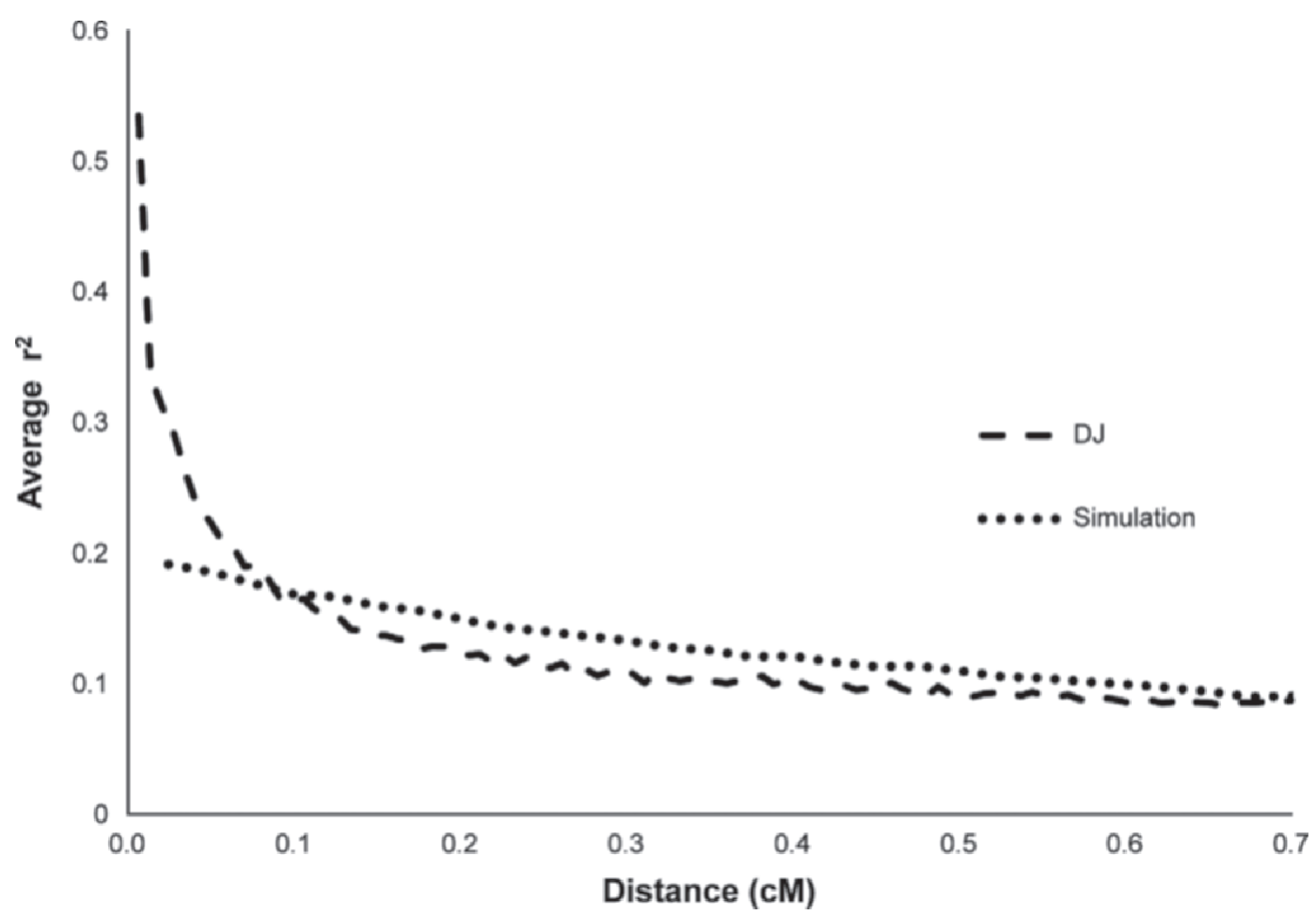

Figure 1. Linkage disequilibrium calculated as average $r^{2}$ for different marker distances (in cM). The DJ line (Thomasen et al., 2013) shows the $r^{2}$ in the Danish Jersey population, and the Simulation line shows the $r^{2}$ in the last generation of the historic population.

testing program for build-up of a reference population consisting of 1,000 progeny-tested genotyped bulls, followed by (3) $15 \mathrm{yr}$ of the genomic selection schemes (turbo or hybrid).

Historic Population. The goal for the formation of the historic population was 2-fold: first, to generate a dense SNP marker set with a LD structure reflecting the Danish Jersey population (Thomasen et al., 2012) and second, to build a genetic architecture fitting the traits included in the breeding goal (Thomasen et al., 2013). The genetic architecture of the traits was modeled by a finite locus model, where traits were influenced by a large but finite number of QTL, each having a small but noninfinitesimal effect.

The historic population was simulated over 500 nonoverlapping generations. In the base generation, 200 males and 200 females were mated. This number was reduced linearly to 125 males and 125 females in the last generation. The genome for each animal contained 30 chromosomes of $100 \mathrm{cM}$ each containing a total of 3 $\times 10^{8}$ evenly distributed potential SNP markers. The base population was completely homozygous. A mutation rate of $1.8 \times 10^{-6}$ converted the original allele to an alternate allele. Every 32nd marker was a potential QTL. If a mutation occurred at a potential QTL, a segregating QTL was generated. After 500 generations, 157,374 markers and 5,055 QTL were segregating.
The LD structure was evaluated by calculating the $\mathrm{r}^{2}$ (Lewontin, 1964) for different marker distances (Figure $1) ; r^{2}$ was calculated as the squared correlation of alleles at pairs of markers that were grouped into bins of 10-kb lengths. All breeding schemes were started by sampling from the haplotypes of the same last generation of the historic population. We assumed the total genetic variance in the historic population for each trait to be 1.0.

Sire Reference Population. The sire reference population was generated over a period of $20 \mathrm{yr}$ (time step 1 to 20) to reflect the current size of the Danish Jersey reference population. Each year, 50 bulls were progeny tested, for a total of 1,000 progeny-tested bulls. Each year, 5 PB were selected for further inseminations. Only PB were used as bull sires in this scheme. A detailed overview of the breeding scheme parameters is given in Table 1 . This breeding scheme models the conventional progeny testing scheme (C-B50) before the start of genomic selection. We used the results from time step 11 to 20 to evaluate the conventional breeding scheme (Table 1).

\section{Breeding Goal and Traits}

The breeding goal included 2 traits. The first trait represented milk production traits $\left(h^{2}=0.30\right)$ and the second represented functional traits $\left(\mathrm{h}^{2}=0.04\right)$. An 
Table 1. Parameters used for modeling of breeding schemes, including the conventional reference breeding scheme for buildup of the sire reference population (C-B50) and 2 future breeding schemes: the hybrid breeding scheme with a combined use of genomic selected young bulls and progeny-tested bulls and the turbo breeding scheme with use of young bulls only ${ }^{1}$

\begin{tabular}{|c|c|c|c|}
\hline Breeding scheme parameter & C-B50 & Hybrid & Turbo \\
\hline Proportion of cows mated with young bulls & 0 & 0.25 & 1.0 \\
\hline No. of proven bulls selected per year & 5 & 4 & - \\
\hline Age distribution of proven bulls (yr) & 5 to 6 & 5 to 6 & - \\
\hline No. of young bulls mated with bull dams & 0 & 15 & 15 \\
\hline Age distribution of bull dams (yr) & 1 to 3 & 1 to 3 & 1 to 3 \\
\hline Number of progeny-tested young bulls ${ }^{1}$ & 50 & $\begin{array}{c}15,40,60,100 \\
50,500\end{array}$ & $\begin{array}{c}15,40,60,100 \\
250,500\end{array}$ \\
\hline Age distribution of young bulls sires ( $\mathrm{yr}$ ) & - & 1 to 4 & 1 to 4 \\
\hline No. of selected bull dams per year & 1,500 & 1,500 & 1,500 \\
\hline No of genotyped bull calves & 0 & 500 & 500 \\
\hline No. of genotyped cows years 21 to $35^{2}$ (per year) & — & $0,2,000$ & $0,2,000$ \\
\hline Additional no. of genotyped cows years 21 and 22 in total ${ }^{2}$ & - & $0,4,000$ & $0,4,000$ \\
\hline
\end{tabular}

${ }^{1}$ Reference value is 60 , but scenarios varied from 15 to 500 bulls.

${ }^{2}$ Reference value is 0 , but a scenario with 2,000 cows was also run.

unfavorable genetic correlation of -0.30 between the 2 traits was assumed. The effects of the QTL affecting the 2 traits were sampled from a bivariate normal distribution and afterward scaled to a variance equal to 1 and resulted in the specified genetic parameters for the 2 traits. The residuals were assumed uncorrelated. The economic values were set to $€ 83$ for the PT and $€ 82$ for the FT per additive genetic standard deviation. These economic values were chosen so the correlation between milk production and breeding goal was the same as in the Nordic total merit index (Buch et al., 2012b). The total merit index for the 2 traits was used as selection criteria for all animals. The variance of the breeding goal is $10,000 €^{2}$ for an unborn calf of unknown sex.

\section{Sampling of Breeding Values and Phenotypes}

The true breeding values (TBV) were constructed by summing the QTL allelic effects within and across loci. The phenotypes were simulated by adding a residual term sampled from a normal distribution with a mean of 0 . A residual variance of 2.33 was used for the PT and 24 for the FT.

\section{Estimation of Breeding Values}

Two different genetic evaluations were used: (1) a single-step genomic BLUP (SS-GBLUP) for prediction of GEBV, and (2) a BLUP animal model using traditional pedigree relationship for prediction of EBV. The SS-GBLUP procedure was used to predict GEBV for the selection of genotyped bull calves to become YB. Conventional BLUP was used to predict EBV in the selection steps of bull dams, cows, and PB.

The procedures for estimation of GEBV using SSGBLUP were previously described (Legarra et al., 2009;
Aguilar et al., 2010; Christensen and Lund, 2010). The genomic relationship matrix $(\mathbf{G})$ was calculated from marker genotype data and scaled to be compatible with the pedigree relationship matrix (A). Due to incomplete LD between markers and QTL, the SNP markers cannot capture all genetic variance explained by the QTL. Therefore, the combined relationship matrix used for the genotyped animals $\left(\mathbf{G}_{w}\right)$ was a linear combination of $\mathbf{G}$ and $\mathbf{A}$, as described by Gao et al. (2012). The $\mathbf{G}_{w}$ was calculated as follows: $\mathbf{G}_{w}=(1-w) \mathbf{G}+w \mathbf{A}$, where $w$ was the weight representing the fraction of genetic variance not captured by markers. In this study, a weight of 0.1 was used, assuming only a small fraction of the genetic variance not explained by the markers. Prediction of GEBV and EBV was done using DMU (Madsen and Jensen, 2008).

\section{Method and Evaluation Criteria}

The stochastic simulation tool ADAM (Pedersen et al., 2009) was used to simulate the different breeding strategies. For the 12 scenarios involving the variable number of progeny-tested YB, 50 replicates of each scenario were performed. Because of long computation times for SS-GBLUP breeding value estimation in the scenarios involving genotyped cows, only 20 replicates were performed for the 4 scenarios involving genotyping cows. Analyses of annual monetary genetic gain $(\Delta \mathbf{G})$, variance of $\Delta G(\mathbf{V})$, and rate of inbreeding per generation $(\Delta \mathbf{F})$ were evaluated in years 21 to 35 .

For each replicate, $\Delta \mathrm{G}$ was calculated as the regression coefficient of mean TBV on birth year of all calves born. In this study, $\Delta \mathrm{G}$ was presented as the mean of replicates for each scenario, and $\mathrm{V}$ was calculated as the variance of $\Delta \mathrm{G}$ between replicates. Inbreeding rates were presented per generation and estimated from 
the pedigree. The inbreeding rate per generation was calculated for each replicate as 1 minus the exponential of the regression coefficient of the natural logarithm of 1 minus mean inbreeding on the average generation equivalent for each year (Falconer and Mackay, 1996). The presented $\Delta \mathrm{F}$ was then obtained by averaging over replicates. The inbreeding rate per year was calculated by dividing the inbreeding rates per generation with the generation interval. Differences in $\Delta \mathrm{G}$ and $\Delta \mathrm{F}$ between scenarios were compared with the least significant difference (LSD) using a confidence level of $95 \%$.

The reliabilities of EBV were calculated as the squared correlation between the EBV and TBV of the available candidates in a specific selection group. The reliabilities were calculated as averages across replicates within each selection group and birth year.

\section{Economic Evaluation}

The software ZPLAN (Willam et al., 2008) was used to evaluate the economic benefits of genotyping cows for the reference population in the hybrid and turbo schemes with progeny testing of $60 \mathrm{YB}$. The ratio between the change in discounted revenue $(\Delta \mathbf{D R})$ and the increased discounted costs $(\Delta \mathbf{D C})$ by adding cows to the reference population was used as the criterion for evaluating whether the investment in genotyping cows was profitable. The investment was assumed to be profitable for a ratio larger than unity $(\Delta \mathrm{DR} / \Delta \mathrm{DC}$ $\geq 1$ ). The discounted revenue (DR) was defined as the monetary revenue based on the genetic superiority and was expressed as the revenue per cow in the population over the investment period of $15 \mathrm{yr}$ discounted by an interest rate of $6 \%$ (Thomasen et al., 2014). The discounted costs (DC) were defined as the variable breeding costs per cow during the investment period of 15 yr discounted by an interest rate of $4 \%$ (Thomasen et al., 2014). An increased discount rate on return was applied in this study, because returns are less certain than costs. The same population parameters, biological coefficients, and costs parameters as in Thomasen et al. (2014) were used. The variable cost parameters related to the breeding scheme are the variable costs covering feeding and labor, which differ between the $\mathrm{H}$ and $T$ schemes. A cost of $€ 60$ per genotyping of a cow was used in the present study for the evaluation of the investment of genotyping the cows. This cost reflects the actual total cost for genotyping with $\sim 10,000 \mathrm{SNP}$ markers, including sampling of tissue (P. G. Larson, VikingGenetics, Randers, Denmark, personal communication). The $\Delta \mathrm{DR} / \Delta \mathrm{DC}$ relationship was evaluated for different levels of gain in reliabilities due to inclusion of cows in the reference compared with the standard genomic hybrid and turbo schemes from Thomasen et al. (2014).

\section{RESULTS}

\section{Updating the Reference Population with Bulls}

For all levels of progeny-tested bulls, the turbo scheme gave significantly $(P<0.05)$ higher annual $\Delta \mathrm{G}$ compared with the hybrid schemes (Table 2). The largest difference between the 2 schemes was for 500 YB progeny tested per year, with a difference of $21.1 \%$. The smallest difference between the 2 schemes was obtained for $15 \mathrm{YB}$, where the turbo scheme was genetically superior by $10.0 \%$. The variance of response for all turbo schemes was in the range from 3.71 to 6.95 . For the hybrid schemes, the interval was from 2.87 to 4.64 .

Varying the number of YB from 15 to 500 provided no significant difference in annual $\Delta G$ for the hybrid schemes. For turbo schemes, progeny testing $500 \mathrm{YB}$ provided the significantly highest annual $\Delta \mathrm{G}$ (€29.92). The genomic schemes always provided significantly $(P$ $<0.05)$ higher $\Delta \mathrm{G}$ compared with C-B50. The H-B60 was $14.6 \%$ superior and the T-B60 was $29.9 \%$ superior.

The increase in inbreeding per generation was lower in the turbo schemes (1.67 to 1.79\%) compared with the hybrid schemes (1.95 to $2.11 \%$ ). The shorter generation interval in the turbo schemes resulted in a significantly higher yearly increase in inbreeding rates $(0.66$ to $0.69 \%$ ) compared with the hybrid schemes (0.53 to $0.55 \%)$. However, only for $15 \mathrm{YB}$ was this difference significant $(P<0.05)$. In the hybrid schemes, usage of bulls was a mixture of YB and PB (Table 1). The generation interval in the hybrid schemes was around $3.75 \mathrm{yr}$. In the turbo schemes, with exclusive use of YB, the generation interval was reduced to approximately $2.60 \mathrm{yr}$.

\section{Updating the Reference Population with Genotyped Cows}

Updating the reference population with genotyped cows provided $€ 5.6$ higher annual $\Delta \mathrm{G}(20 \%)$ in the turbo scheme compared with the hybrid scheme (Table $3)$. The COW4000 provided a nonsignificant improvement over COW2000 in annual $\Delta \mathrm{G}$ in both the hybrid (€0.42) and the turbo scheme (€0.14). In the cow schemes, V ranged from 1.63 in the H-COW2000 and up to 4.71 in the H-COW4000.

Compared with the hybrid scheme (H-B60) in Table 2, H-COW2000 provided €2.42 (9.7\%) higher annual $\Delta \mathrm{G}$, whereas T-COW2000 yielded $€ 6.74(23.9 \%)$ higher annual $\Delta \mathrm{G}$ compared with the T-B60 scheme. The H- 
Table 2. Annual monetary genetic gain $(\Delta \mathrm{G})$, variance of $\Delta \mathrm{G}$ across replicates $(\mathrm{V})$, generation interval (GI), and rate of inbreeding in percentage per generation $(\Delta \mathrm{F} /$ gen $)$ and per year $(\Delta \mathrm{F} /$ year $)$ averaged over years 21 to 35 and averaged over 50 replicates for the hybrid $(\mathrm{H})$ and turbo $(\mathrm{T})$ breeding schemes and varied number of young bulls (B) tested (SE in parentheses)

\begin{tabular}{llllll}
\hline Scheme & \multicolumn{1}{c}{$\Delta \mathrm{G}$} & $\mathrm{V}$ & $\mathrm{GI}$ & $\Delta \mathrm{F} /$ gen $(\%)$ & $\Delta \mathrm{F} /$ year $(\%)$ \\
\hline C-B50 & $21.67^{\mathrm{e}}(0.024)$ & 0.36 & 4.67 & $1.80^{\mathrm{a}}(0.005)$ & $0.39^{\mathrm{a}}(0.001)$ \\
H-B15 & $24.46^{\mathrm{a}}(0.266)$ & 3.53 & 3.83 & $2.11^{\mathrm{b}}(0.068)$ & $0.55^{\mathrm{b}}(0.018)$ \\
T-B15 & $26.91^{\mathrm{b}}(0.373)$ & 6.95 & 2.65 & $1.74^{\mathrm{a}}(0.053)$ & $0.66^{\mathrm{c}}(0.020)$ \\
H-B40 & $25.26^{\mathrm{a}}(0.254)$ & 3.23 & 3.77 & $1.99^{\mathrm{ab}}(0.072)$ & $0.53^{\mathrm{b}}(0.019)$ \\
T-B40 & $28.00^{\mathrm{bc}}(0.312)$ & 4.86 & 2.61 & $1.79^{\mathrm{a}}(0.059)$ & $0.69^{\mathrm{c}}(0.023)$ \\
H-B60 & $24.83^{\mathrm{a}}(0.240)$ & 2.88 & 3.70 & $1.98^{\mathrm{ab}}(0.056)$ & $0.54^{\mathrm{b}}(0.015)$ \\
T-B60 & $28.15^{\mathrm{bc}}(0.335)$ & 5.61 & 2.61 & $1.75^{\mathrm{a}}(0.056)$ & $0.67^{\mathrm{c}}(0.021)$ \\
H-B100 & $24.73^{\mathrm{a}}(0.240)$ & 2.87 & 3.69 & $1.96^{\mathrm{ab}}(0.059)$ & $0.53^{\mathrm{b}}(0.016)$ \\
T-B100 & $28.15^{\mathrm{bc}}(0.272)$ & 3.71 & 2.59 & $1.67^{\mathrm{a}}(0.060)$ & $0.64^{\mathrm{c}}(0.023)$ \\
H-B250 & $24.85^{\mathrm{a}}(0.240)$ & 2.87 & 3.71 & $1.97^{\mathrm{ab}}(0.056)$ & $0.53^{\mathrm{b}}(0.015)$ \\
T-B250 & $29.09^{\mathrm{cd}}(0.326)$ & 5.31 & 2.58 & $1.79^{\mathrm{ab}}(0.065)$ & $0.69^{\mathrm{c}}(0.025)$ \\
H-B500 & $24.71^{\mathrm{a}}(0.305)$ & 4.64 & 3.66 & $1.95^{\mathrm{ab}}(0.052)$ & $0.53^{\mathrm{b}}(0.014)$ \\
T-B500 & $29.92^{\mathrm{d}}(0.322)$ & 5.17 & 2.56 & $1.77^{\mathrm{ab}}(0.053)$ & $0.69^{\mathrm{c}}(0.021)$ \\
\hline
\end{tabular}

${ }^{\mathrm{a}-\mathrm{e}}$ Values within a column with different letters differ significantly $(P<0.05)$.

${ }^{1}$ The figures for the conventional breeding scheme (C-B50) are average of years 11 to 20 for 600 replicates.

COW4000 provided €2.84 (11.4\%) higher annual $\Delta \mathrm{G}$ than the H-B60. For T-COW4000, the difference from the T-B60 was $€ 6.88$ (24.4\%).

Genotyping of cows reduced the rate of inbreeding. For H-COW2000, the rate of inbreeding was reduced by $23.2 \%$ per generation compared with the H-B60 scheme. For T-COW2000, the rate of inbreeding per generation was reduced by $17.1 \%$ compared with the T-B60 scheme.

\section{Reliabilities of GEBV}

The development in reliabilities for genotyped bull calves in the 3 turbo schemes (T-B60, T-COW2000, and T-COW4000) is shown in Figure 2. In the T-B60 scheme, the reliability increased only slightly over the period of $15 \mathrm{yr}$, with an average of 0.19 in the first 5 yr and reaching a level of 0.27 on average over the last years. The reliability of BLUP parent-average EBV was 0.10 in year 21 (results not shown), and hence the gain in reliability due to genomic information in the sire reference population was 0.09 .
The T-COW2000 and T-COW4000 schemes showed a larger increase in reliability during the first 5 yr than in the last $10 \mathrm{yr}$ of the evaluation period. After this period, reliability increased at a lower rate. Adding 4,000 extra cows in the reference population in years 21 and 22 (T-COWS4000) resulted in a higher reliability of GEBV up to year 25 than in T-COWS2000. After this period, we observed no differences between reliabilities in the 2 strategies. For both schemes, reliability increased from approximately 0.3 to just below 0.6.

Figure 3 shows the development in reliabilities for genotyped bull calves in the 3 hybrid schemes H-YB60, $\mathrm{H}-\mathrm{COW} 2000$, and H-COW4000. The development in reliabilities followed the same pattern at a slightly higher level as for the turbo schemes.

\section{Economic Evaluation of Genotyping Cows}

Table 4 shows the economic benefit of including genotyped cows in the reference population. In the present study, the gain in reliability on average of the hybrid scheme and turbo scheme was +0.38 over the

Table 3. Annual monetary genetic gain $(\Delta \mathrm{G})$, variance of response $(\mathrm{V})$, generation interval (GI), and rate of inbreeding in percentage per generation $(\Delta \mathrm{F} /$ gen $)$ and per year $(\Delta \mathrm{F} /$ year $)$ averaged over years 21 to 35 and average of 20 replicates for different breeding schemes and different strategies for genotyping of cows (SE in parentheses)

\begin{tabular}{lccccc}
\hline Scheme $^{1}$ & $\Delta \mathrm{G}$ & $\mathrm{V}$ & $\mathrm{GI}$ & $\Delta \mathrm{F} /$ gen $(\%)$ & $\Delta \mathrm{F} /$ year $(\%)$ \\
\hline H-COW2000 & $27.25^{\mathrm{a}}(0.286)$ & 1.63 & 3.58 & $1.52^{\mathrm{b}}(0.076)$ & $0.42^{\mathrm{a}}(0.021)$ \\
H-COW4000 & $27.67^{\mathrm{a}}(0.485)$ & 4.71 & 3.61 & $1.76^{\mathrm{c}}(0.114)$ & $0.49^{\mathrm{a}}(0.032)$ \\
T-COW2000 & $34.89^{\mathrm{b}}(0.436)$ & 3.80 & 2.44 & $1.44^{\mathrm{ab}}(0.076)$ & $0.59^{\mathrm{a}}(0.031)$ \\
T-COW4000 & $35.03^{\mathrm{b}}(0.329)$ & 2.16 & 2.45 & $1.21^{\mathrm{a}}(0.064)$ & $0.49^{\mathrm{a}}(0.026)$ \\
\hline
\end{tabular}

${ }^{\mathrm{a}-\mathrm{c}}$ Values within a column with different letters differ significantly $(P<0.05)$.

${ }^{1} \mathrm{Hybrid}$ (H; a mix of genotyped young bulls and progeny-tested bulls) and turbo ( $\mathrm{T}$; genotyped young bulls only) breeding schemes for different strategies of genotyping cows [2,000 first-lactation cows randomly genotyped (COW2000); 2,000 first-lactation cows randomly genotyped (COW4000)]. 


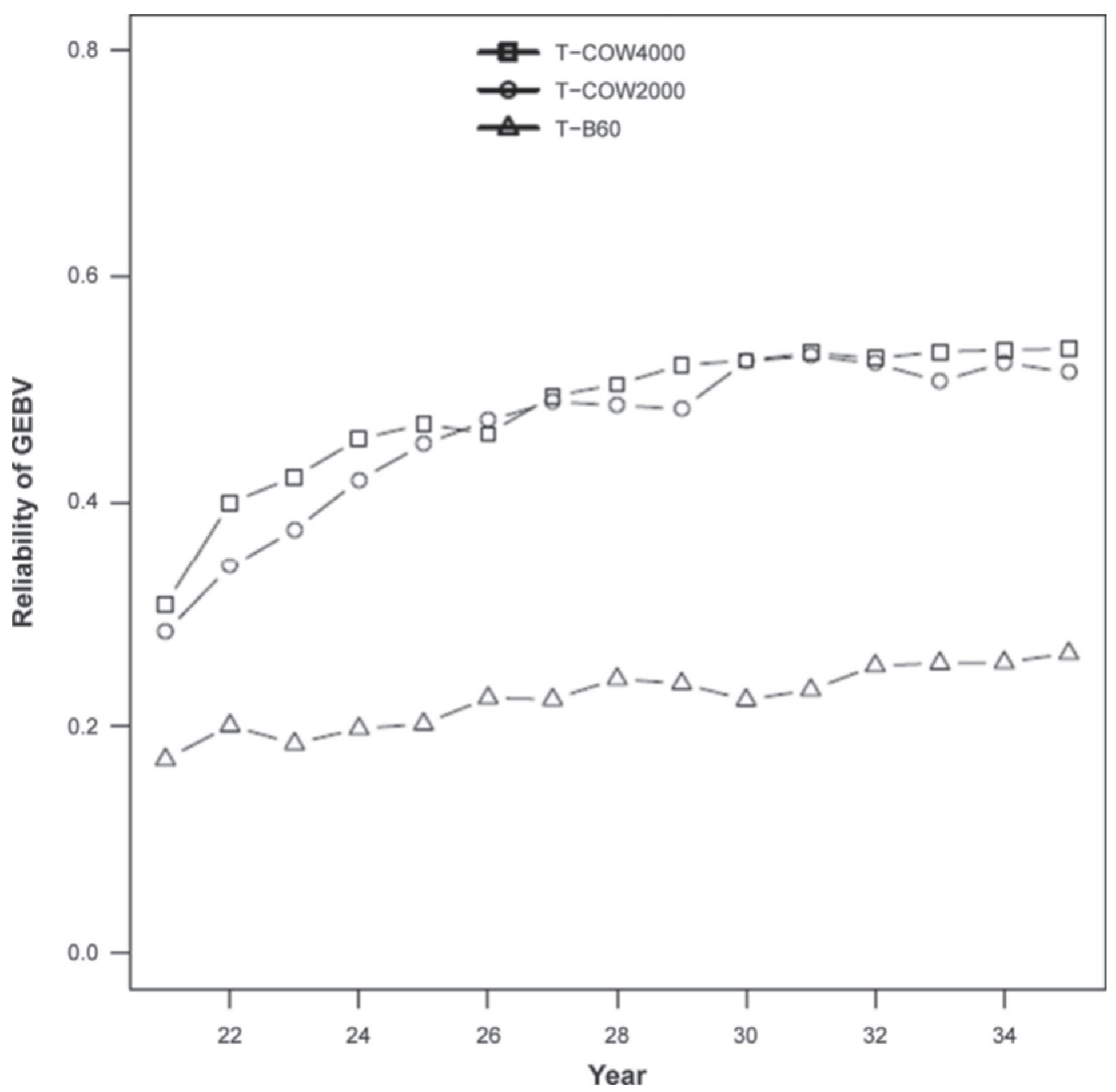

Figure 2. Development in reliability of genomically enhanced breeding values (GEBV) of genotyped bull calves over time for the turbo schemes $(\mathrm{T})$ adding progeny-tested young bulls to the reference population (T-B60), and genotyped cows to the reference population (T-COW2000 and T-COW4000).

evaluation period of $15 \mathrm{yr}$. In the hybrid scheme, the return on investment was 12.4 -fold, assuming this increase in reliability. The cost of genotyping the cows was returned in full at an increase in reliability of at least 0.03 . In the hybrid scheme, the cost of genotyping cows contributed $20.6 \%$ of the total variable cost of the breeding scheme. For an increase in reliability of 0.1, the return on investment was 3.44-fold.

In the turbo scheme, the investment in genotyping cows was returned in full at a gain in reliability just over 0.01 . At a gain in reliability of 0.03 , the break-even value for the hybrid scheme, the return on investment was 5.04 -fold. The gain in reliability from incorporation of cows in the reference population found in the present study was 0.38 . With this value, the return on investment was 52.4-fold. The cost of genotyping cows contributed $44.7 \%$ of the total variable cost of the turbo scheme.

\section{DISCUSSION}

Inclusion of cows in the reference population was profitable, and it constitutes a fast way to increase reliabilities of genomic predictions while also reducing rate of inbreeding and risk. Genotyping of cows for inclusion in the reference population increased genetic gain and decreased the rate of inbreeding compared with breeding schemes that only updated reference populations with progeny-tested bulls. This increase in genetic gain was greater for turbo schemes characterized by exclusive use of YB and hence shorter generation intervals. The risk, measured as variance of response, was gener- 
Table 4. The relationship between the change in discounted revenue and the increased discounted costs $(\Delta \mathrm{DR} / \Delta \mathrm{DC})$ by genotyping 2,000 cows yearly for the reference population assuming varied gain in reliability of genomic breeding values by adding genotyped cows to the reference population in the hybrid and turbo schemes

\begin{tabular}{lcc}
\hline & \multicolumn{2}{c}{$\Delta \mathrm{DR} / \Delta \mathrm{DC}$} \\
\cline { 2 - 3 } Gain in \\
reliability & Hybrid & Turbo \\
\hline 0.01 & 0.17 & 0.80 \\
0.02 & 0.83 & 4.31 \\
0.03 & 1.00 & 5.04 \\
0.05 & 1.78 & 8.95 \\
0.1 & 3.44 & 16.5 \\
0.2 & 6.89 & 31.2 \\
0.3 & 9.94 & 43.2 \\
0.38 & 12.4 & 52.4 \\
\hline
\end{tabular}

ally higher for the turbo schemes with genotyping of males compared with the schemes using progeny-tested bulls. This was due to the lower reliability of the bulls used intensively.

\section{Value of Genotyping Cows}

Adding genotypes of cows had a major positive effect on reliabilities of GEBV. We proposed genotyping of cows to update and enlarge the reference population for a small population with a small reference population and a limited annual number of progeny-tested bulls. Sixty bulls progeny tested annually resulted in only a minor increase in reliability of the genomic predictions $(+0.07)$ over the $15 \mathrm{yr}$ in both the turbo scheme and the hybrid scheme. After $4 \mathrm{yr}$, with genotyping of a total of 8,000 cows in COW2000 scheme, the reliability of GEBV was increased by +0.20 . After the fifth year with genotyping of cows, reliability increased at a lower rate, where the added information from the genotyped cows and progeny-tested bulls was sufficient to offset the decreased value (aging) of the information from the historic sire reference population.

For the hybrid and turbo breeding schemes, genotyping of cows was shown to be a highly profitable investment. Only small gains in reliabilities (0.01 to 0.03 ) were required to break even on the investment. The cost-benefit analysis assumed that the total revenue was returned to the investor, which might not be the case in a competing market. However, even at gains in reliability on the order of 0.10 , there was a high return on the investment (more than 3 -fold), so the investment would be profitable even if the revenue was only partly returned to the breeding company.

Depending on the breeding scheme applied, the increase in genetic gain by including cows in the reference varied between 14 and 26\%. McHugh et al. (2011) studied the value of including cows in the reference popula- tion for a small dairy cattle population with 500 bulls in the reference population. The genetic gain increased $9 \%$ by adding 500 genotyped cows to the reference and increased $44 \%$ by adding 3,500 genotyped cows to the reference population annually. The marginal value of including cows was found to be higher, because the reference population in the study by McHugh et al. (2011) was only half the size of that in the present study.

The genotyped cows were randomly chosen from the approximately 5,000 first-lactation cows. However, strategies for selection of the genotyped females may affect reliabilities of GEBV. Pszczola et al. (2012) showed that the family structure in the reference population influences the reliability of GEBV. The highest reliability of GEBV was obtained when the relationship between animals in the reference population was lowest. Therefore, strategies that minimize the relationship between the cows chosen for genotyping are expected to produce the largest improvements in reliability; for example, strategies that ensure a balanced family size of genotyped cows. In contrast, the degree of relationship between animals in the reference and selection candidates should be maximized (Pszczola et al., 2012). The bull dam candidates were not genotyped in the setup for our study. This was done solely to evaluate the effect on monetary genetic gain of including genotyped production cows in the reference population, without changing the selection criteria and reliability of bull dam candidates. However, using genotype information in selection of females will result in increased reliabilities of young bull dam candidates without their own performance records and hence reduce the generation interval in this selection path and increase genetic gain. Dassonneville et al. (2012) showed that inclusion of elite females in the reference population leads to overestimated genomic predictions for production traits due to biased phenotypes. Therefore, if preferential treatment exists, inclusion of genotyped bull dam candidates in the reference population will probably not benefit the genomic predictions.

It was consistently better to add cows to the reference population than to only add progeny-tested bulls, even when many bulls were progeny tested. In the turbo scheme, increasing the number of progeny-tested bulls increased the reliability of genomic predictions and consequently genetic gain. However, in the hybrid schemes, the increased reliability of genomic predictions was offset by a reduced reliability of the progenytested bulls, which were used for $75 \%$ of the matings. Consequently, progeny testing more bulls with smaller daughter groups was only an option for increasing genetic gain, when the progeny-tested bulls were not used intensively. 


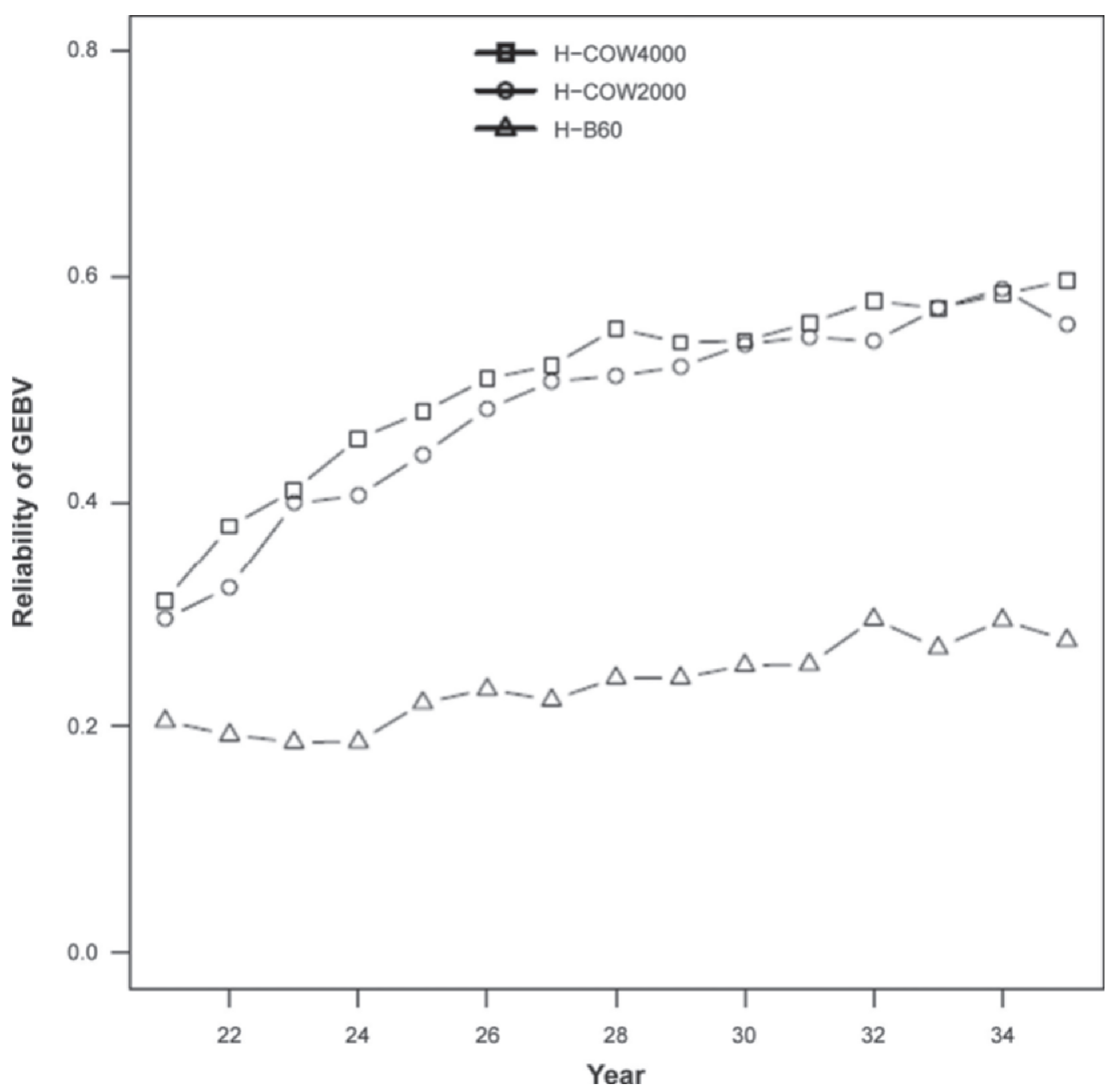

Figure 3. Development in reliability of genomically enhanced breeding values (GEBV) of genotyped bull calves over time for the hybrid schemes $(\mathrm{H})$ adding progeny-tested young bulls to the reference population (H-B60) and genotyped cows to the reference population (H-COW2000 and H-COW4000).

\section{Inbreeding}

Without genomic information, candidates without their own phenotypic information or offspring information have breeding values based on their parents' information. Genomic information adds information about the Mendelian sampling term for young selection candidates. Information about Mendelian segregation leads to more efficient selection within families and relatively less between-family selection; consequently, GS is expected to reduce rate of inbreeding per generation compared with traditional BLUP selection, assuming the same breeding scheme (Daetwyler et al., 2007). In the present study, the lowest rate of inbreeding was seen for the schemes adding cows to the reference population compared with the schemes where only progeny-tested bulls were used to update the reference population, because relatively less between-family selection was performed due to higher reliabilities of Mendelian sampling terms.

In GS breeding schemes where the reference population consists only of bulls, the general expectation is that GS schemes would provide lower rates of inbreeding compared with conventional breeding schemes; however, we did not observe this in the current study. There are 2 possible explanations. First, the gain in reliability due to genomic information was low and hence information about the Mendelian sampling term remained inaccurate, so the selection of young animals was mostly across-family selection. Second, the genomic hybrid schemes used a few PB quite intensively, so the average relatedness of the next generation was high. 
Selection of breeding candidates with a lower reliability increased the risk of the breeding schemes. In breeding schemes with only males in the reference population, we found a lower average variance of response in the hybrid schemes compared with the turbo schemes. The latter selection decisions are based on GEBV with lower reliabilities because no PB bulls were used. In the schemes adding cows to the reference population, this conclusion could not be verified. With the low number of replicates in the schemes, including more replicates is necessary to confirm this finding. In the turbo schemes, adding cows to the reference population reduced the risk because the reliability increased and the uncertainty in decision making decreased.

\section{Gain in Reliability}

The reliabilities of GEBV obtained by SS-GBLUP were 10 percentage points higher than those of traditional parent averages obtained from traditional BLUP estimates. This gain was twice the gain recently estimated from real data in the Danish Jersey population with 1,000 reference bulls (Thomasen et al., 2012). Several factors might explain this finding. First, we were unaware of the true genetic architecture of the traits. In this study, 5,055 purely additive QTL explained the additive genetic variance of the traits. We used 157,374 segregating markers, many of which had low minor allele frequencies. In the real Danish Jersey population, 38,242 markers are segregating (Thomasen et al., 2012). However, this is a selected set of SNP markers biased toward high minor allele frequency. The effect of this difference is unknown, because we do not know how SNP at low frequencies contribute to tracking the QTL explaining the total breeding value. In addition, other genetic effects besides additive genetic effects might be present and complicate prediction.

The level of LD between the QTL and the markers tracking the QTL is also known to influence the reliability of GEBV. If the distance is 0.1 to $0.7 \mathrm{cM}$, then the LD in this simulation study was higher compared with the level of LD in the real population (Figure 1) and results in higher reliabilities of genomic predictions. For short marker-QTL distances $(<0.1 \mathrm{cM})$, the LD is too low in simulated data. However, in real data, the average distance from the QTL to the nearest marker is unknown and, thus, consequences of this difference are difficult to anticipate.

\section{Optimal Breeding Schemes}

Turbo schemes were always superior to the hybrid schemes, regardless of the number of progeny-tested bulls. In the turbo scheme, a higher genetic gain could be obtained by increasing the number of progeny-tested bulls. Thomasen et al. (2014) found that, in a deterministic simulation study using similar parameters, the optimal design of the breeding scheme depended on the reliabilities of GEBV. That study showed that a turbo scheme became genetically superior when the gain in reliability was 10 percentage points. However, for a smaller increase in reliabilities $(+5$ percentage points), the optimal breeding scheme still involved intensive use of progeny-tested bulls. Further investigation to clarify the optimal number of $\mathrm{YB}$, when cows are included in the reference population, would be beneficial, both from a genetic perspective in a hybrid scheme and from an economic perspective, as progeny testing of bulls is a costly process.

\section{ACKNOWLEDGMENTS}

This work was performed in the project "Genomic Selection - from function to efficient utilization in cattle breeding (grant no. 3412-08-02253)," funded by the Danish Directorate for Food, Fisheries and Agri Business (Copenhagen, Denmark), Mælkeafgiftsfonden, VikingGenetics (Randers, Denmark), Nordic Genetic Evaluation (Aarhus, Denmark), and Aarhus University (Aarhus, Denmark). The work was co-funded by a PhD scholarship from VikingGenetics and the Ministry of Science, Technology and Innovation.

\section{REFERENCES}

Aguilar, I., I. Misztal, D. L. Johnson, A. Legarra, S. Tsuruta, and T. J. Lawlor. 2010. Hot topic: A unified approach to utilize phenotypic, full pedigree, and genomic information for genetic evaluation of Holstein final score. J. Dairy Sci. 93:743-752.

Buch, L. H., M. Kargo, P. Berg, J. Lassen, and A. C. Sørensen. 2012a. The value of cows in reference populations for genomic selection of new functional traits. Animal 6:880-886.

Buch, L. H., M. K. Sørensen, P. Berg, L. D. Pedersen, and A. C. S $\varnothing-$ rensen. 2012b. Genomic selection strategies in dairy cattle: Strong positive interaction between use of genotypic information and intensive use of young bulls on genetic gain. J. Anim. Breed. Genet. 129:138-151.

Christensen, O., and M. Lund. 2010. Genomic prediction when some animals are not genotyped. Genet. Sel. Evol. 42:2.

Daetwyler, H. D., B. Villanueva, P. Bijma, and J. A. Woolliams. 2007. Inbreeding in genome-wide selection. J. Anim. Breed. Genet. 124:369-376.

Dassonneville, R., A. Baur, S. Fritz, D. Boichard, and V. Ducrocq. 2012. Inclusion of cow records in genomic evaluations and impact on bias due to preferential treatment. Genet. Sel. Evol. 44:40.

Falconer, D. S., and T. F. C. Mackay. 1996. Introduction to Quantitative Genetics. 4th ed. Longman, New York, NY.

Gao, H., O. Christensen, P. Madsen, U. Nielsen, Y. Zhang, M. Lund, and G. Su. 2012. Comparison on genomic predictions using three GBLUP methods and two single-step blending methods in the Nordic Holstein population. Genet. Sel. Evol. 44:8.

Lauritsen, U. 2012. Tal om Kvæg. Monthly statistics. Accessed Sep. 18, 2013. http://www.landbrugsinfo.dk/Kvaeg/Tal-om-kvaeg/ Sider/mndstatmain.aspx.

Legarra, A., I. Aguilar, and I. Misztal. 2009. A relationship matrix including full pedigree and genomic information. J. Dairy Sci. 92:4656-4663. 
Lewontin, R. C. 1964. The interaction of selection and linkage: I. General considerations; heterotic models. Genetics 49:49-67.

Lund, M. S., A. de Roos, A. de Vries, T. Druet, V. Ducrocq, S. Fritz, F. Guillaume, B. Guldbrandtsen, Z. Liu, R. Reents, C. Schrooten, F. Seefried, and G. Su. 2011. A common reference population from four European Holstein populations increases reliability of genomic predictions. Genet. Sel. Evol. 43:43.

Madsen, P., and J. Jensen. 2008. A User's Guide to DMU. Version 6 release 4.7. Aarhus University, Foulum, Denmark.

McHugh, N., T. H. E. Meuwissen, A. R. Cromie, and A. K. Sonesson. 2011. Use of female information in dairy cattle genomic breeding programs. J. Dairy Sci. 94:4109-4118.

Meuwissen, T. H. E., B. J. Hayes, and M. E. Goddard. 2001. Prediction of total genetic value using genome-wide dense marker maps. Genetics 157:1819-1829.

Pedersen, L. D., A. C. Sørensen, M. Henryon, S. Ansari-Mahyari, and P. Berg. 2009. ADAM: A computer program to simulate selective breeding schemes for animals. Livest. Sci. 121:343-344.

Pszczola, M., T. Strabel, H. A. Mulder, and M. P. L. Calus. 2012. Reliability of direct genomic values for animals with different relationships within and to the reference population. J. Dairy Sci. 95:389-400.

Thomasen, J. R., C. Egger-Danner, A. Willam, B. Guldbrandtsen, M. S. Lund, and A. C. Sørensen. 2014. The optimal genomic selec- tion breeding scheme in a small dairy cattle breeding scheme still involves progeny testing. J. Dairy Sci. 97:458-470.

Thomasen, J. R., B. Guldbrandtsen, G. Su, R. F. Brøndum, and M. S. Lund. 2012. Reliabilities of genomic estimated breeding values in Danish Jersey. Animal 6:789-796.

Thomasen, J. R., A. C. Sørensen, B. Guldbrandtsen, G. Su, P. Madsen, and M. S. Lund. 2013. The admixed population structure in Danish Jersey challenge accurate genomic predictions. J. Anim. Sci. 91:3105-3112.

Van Grevenhof, E. M., J. A. M. van Arendonk, and P. Bijma. 2012 Response to genomic selection: The Bulmer effect and the potential of genomic selection when the number of phenotyped records is limited. Genet. Sel. Evol. 44:26.

Wiggans, G. R., P. M. VanRaden, and T. A. Cooper. 2011. The genomic evaluation system in the United States: Past, present, future. J. Dairy Sci. 94:3202-3211.

Willam, A., G. Nitter, H. Bartenschlager, K. Karras, E. Niebel, and H.-U. Graser. 2008. ZPLAN-Manual for a PC-Program to Optimize Livestock Selection Schemes. Manual Version 2008 for Source Code "z10.for". University of Natural Resources and Applied Life Sciences, Department of Sustainable Agricultural Systems, Division Livestock Sciences, Vienna, Austria. 